\title{
A construção do conhecimento na leitura e escrita e a intervenção psicopedagógica
}

\author{
The construction of knowledge of reading and writing and psycho-pedagogical intervention \\ La construcción del conocimiento de lectura y escritura e intervención psicopedagógica
}

Recebido: 18/04/2021 | Revisado: 23/04/2021 | Aceito: 26/04/2021 | Publicado: 10/05/2021

\author{
Maria do Carmo Gonçalves da Silva Lima \\ ORCID: https://orcid.org/0000-0002-3317-6390 \\ Universidade Estadual de Maringá, Brasil \\ E-mail: mcgs.lima@hotmail.com
}

\begin{abstract}
Resumo
A presente pesquisa tem como objetivo analisar o processo de construção da leitura e da escrita e a intervenção psicopedagógica na alfabetização. No desenvolvimento da pesquisa e para a compreensão de como se dá o processo de construção da leitura e da escrita, a Teoria da Psicogênese da Escrita, elaborada por Ferreiro e Teberosky (1985), foi utilizada para a análise do processo de aquisição e aprendizado no início da alfabetização. Para a fundamentação do trabalho, foi utilizada a pesquisa bibliográfica com análise de livros, teses, dissertações e artigos que versam sobre o tema. Como resultado da pesquisa, concluímos que, para sanar as dificuldades de aprendizagem, compreende-se que é necessário o conhecimento, por parte do psicopedagogo, dos métodos de alfabetização tendo como objetivo contribuir para o processo da aquisição da leitura e da escrita dos aprendizes, privilegiando as especificidades de cada indivíduo.
\end{abstract}

Palavras-chave: Ensino; Leitura; Escrita; Intervenção; Psicopedagógica.

\begin{abstract}
This research aims to analyze the process of construction of reading and writing and the psychopedagogical intervention in literacy. In the development of research and to understand how the process of construction of reading and writing takes place, the Theory of Psychogenesis of Writing, developed by Ferreiro and Teberosky (1985), was used for the analysis of the process of acquisition and learning in beginning of literacy. For the foundation of the work, bibliographic research was used with analysis of books, theses, dissertations and articles dealing with the theme. As a result of the research, we conclude that, in order to remedy the learning difficulties, it is understood that it is necessary for the psychopedagogue to know the literacy methods with the objective of contributing to the process of acquiring the reading and writing of the apprentices, privileging the specificities of each individual.
\end{abstract}

Keywords: Teaching; Reading; Writing; Intervention; Psychopedagogical.

\section{Resumen}

Esta investigación tiene como objetivo analizar el proceso de construcción de la lectura y la escritura y la intervención psicopedagógica en la alfabetización. En el desarrollo de la investigación y para comprender cómo ocurre el proceso de construcción de la lectura y la escritura, se utilizó la Teoría de la Psicogénesis de la escritura, desarrollada por Ferreiro y Teberosky (1985), para el análisis del proceso de adquisición y aprendizaje en el comienzo de alfabetización. Para la fundamentación del trabajo se utilizó la investigación bibliográfica con análisis de libros, tesis, disertaciones y artículos relacionados con el tema. Como resultado de la investigación, concluimos que, para remediar las dificultades de aprendizaje, se entiende que es necesario que el psicopedagogo conozca los métodos de alfabetización con el objetivo de contribuir al proceso de adquisición de la lectura y escritura de los aprendices, privilegiando las especificidades de cada individuo.

Palabras clave: Enseñanza; Lectura; Escritura; Intervención; Psicopedagógico.

\section{Introdução}

De acordo com as estatísticas do MEC (Ministério da Educação e Cultura), muitas/os alunas/os chegam aos anos finais do ensino fundamental sem adquirir as competências de leitura e escrita definidas no currículo escolar. São diferentes dificuldades apresentadas como na leitura, escrita, erros ortográficos, que se não forem sanados nos anos inicias, poderão repercutir por todo o processo escolar, trazendo problemas futuros.

Diante disso, o processo de construção da aquisição da leitura e escrita, precisa ser bem consolidado para não acarretar dificuldades posteriores e, assim, se avolumar em dificuldades mais graves. Compreendendo que a sociedade atual 
está intrinsicamente construída na leitura e escrita, a aquisição dessas competências é essencial para a inserção do indivíduo em sociedade, de modo que possa desfrutar e participar das atividades nela envolvida.

No entanto, diante das estatísticas apresentadas pelo MEC, acerca da enorme quantidade de pessoas com dificuldades de alfabetização, compreende-se que, caso não haja um acompanhamento adequado e sistematizado que objetive a superação desses problemas, essas dificuldades poderão perdurar por toda vida. Nesse sentido, a pesquisa buscou responder aos seguintes questionamentos: Como se dá a construção dos conhecimentos sobre a leitura e a escrita mediante a intervenção psicopedagógica? Para o enfrentamento das dificuldades de aprendizagem no processo de alfabetização, como a psicopedagogia pode contribuir no sentido de intervir para sanar essas dificuldades?

Consideramos a importância de se realizar esta investigação, devido à compreensão que temos acerca da relevância da intervenção psicopedagógica, no sentido de prevenir e também propor estratégias para superação das dificuldades, ao diagnosticar e atuar junto aos demais profissionais capacitados, considerando a demanda das dificuldades crescentes no processo de construção da alfabetização.

\section{Metodologia}

No desenvolvimento da pesquisa, foi utilizada a pesquisa bibliográfica e qualitativa, com análise de fontes diversas que versam sobre o tema. Para Pereira (2018), o artigo científico é um documento que permite revisões de literaturas de modo simplificado, facilitando a exposição do tema em estudo. Assim, nossa pesquisa pretende reunir diferentes autores que abordam o tema da aquisição da leitura e escrita.

Quanto a análise do processo de construção da leitura e escrita, consideramos a Teoria da Psicogênese da Escrita, elaborada por Ferreiro e Teberosky (1985) em seus aspectos linguísticos, significativos quanto à alfabetização. A estrutura teórico-metodológica utilizada pelas pesquisadoras é fornecida pelo construtivismo de Jean Piaget $(1987)^{1}$, em que apresenta o desenvolvimento da criança como constituinte da interação com o seu meio e se desenvolve ao longo de estágios.

As psicolinguistas argentinas Emília Ferreiro e Ana Teberosky, em 1974 iniciaram uma investigação tendo como objetivo compreender como ocorre o processo de aquisição da leitura e escrita pela criança. Assim, constataram que antes mesmo de iniciar os estudos escolares, a criança adquire ideias e faz hipóteses sobre o código escrito, por meio de sua interação com o objeto do conhecimento no meio em que está inserida.

Desta forma, nossa análise parte da premissa de que o processo de construção da aprendizagem, ocorre mediante a atividade interativa do sujeito e, compreender esses aspectos torna-se fundamental para a atuação e intervenção psicopedagógica no ambiente de ensino.

\section{A Construção do Conhecimento da Leitura e Escrita}

No contexto da sociedade do século XXI, a aquisição da leitura e da escrita são competências essenciais para a inserção das pessoas nos diferentes aspectos sociais e profissionais. Saber ler e escrever torna-se imprescindível para a participação e sobrevivência do indivíduo em sociedade. Assim, o desenvolvimento das competências de leitura e escrita permite ao indivíduo obter experiências no mundo letrado e participar ativamente nos diferentes contextos sociais.

\footnotetext{
1 “O construtivismo procura explicar como a inteligência humana se desenvolve partindo do princípio de que o desenvolvimento da inteligência é determinado pelas ações mútuas entre o indivíduo e o meio, ou seja, o homem não é passivo sob a influência do meio, isto é, ele responde aos estímulos externos agindo sobre eles para construir e organizar o seu próprio conhecimento, de forma cada vez mais elaborada" (Niemann; Brandoli, 2012, p. 01).
} 
Dessa forma, a pesquisadora Magda Soares (2004) defende é por meio do processo de alfabetização que são desenvolvidas as habilidades de leitura e escrita. Segundo a autora, a alfabetização é "um processo de aquisição e apropriação do sistema convencional de escrita alfabética e ortográfico" (Sares, 2004, p. 16).

Para Magda Soares, o processo de alfabetização é dotado de métodos amplos e variados, não abrangendo apenas os processos de codificação (escrita) e decodificação (leitura). Como também, a relação entre letramento e alfabetização estão integrados entre si, pois um pode contribuir para o desenvolvimento do outro.

No entanto, para que o processo de alfabetização seja bem consolidado, é importante compreender as suas especificidades. A utilização de métodos eficazes, diretos e sistemáticos, são essenciais para a consolidação da alfabetização. De acordo com Soares (2004, p. 13), esse processo é constituído pela: [...] "consciência fonêmica, phonics (relações fonemagrafema), fluência em leitura (oral e silenciosa), vocabulário e compreensão. O ensino deve ser direto, explícito e sistemático".

Percebe-se então que, sem a compreensão para a utilização desses métodos sistematizados, poderá ocorrer lacunas no processo de alfabetização e possíveis dificuldades de aprendizagem. Concordamos com as pesquisadoras Oliveira (2004) e Moura (2001) quando afirmam que, mesmo diante das mudanças teóricas produzidas na atualidade, a realidade escolar em muitos lugares, demonstra permanecer a utilização de práticas metodológicas tradicionais na forma de ensino que não condizem com as reais necessidades dos aprendizes.

Nas análises da pesquisadora Beatriz Vieira Mendes (2017, p. 8): “Atualmente, o processo de aquisição da leitura e escrita inicia-se, formalmente, aos 6 anos de idade com o ingresso do aluno no $1^{\circ}$ ano do Ensino Fundamental, como determina a Lei 9.394/96". No entanto, Emília Ferreiro e Ana Teberosky (1979) afirmam que antes dos 6 anos, a criança já participa do mundo letrado no contato com os diferentes meios de comunicação como a televisão, os cartazes publicitários, os brinquedos e, podemos acrescentar, a internet, o celular, os jogos eletrônicos, atualmente. Dessa forma, a criança adquire contato com a leitura e a escrita, sem, no entanto, compreendê-las.

Essa compreensão se dará no contexto formal de ensino, em que a figura do professor é fundamental, como mediador no processo de construção da compreensão da aprendizagem. Nas análises de Mendes (2017, p. 8): "O sujeito é ativo na aquisição de tais competências e, também, o construtor do seu processo de alfabetização. E, então, o papel que cabe ao professor é o de mediador de tal processo, favorecendo e estimulando a aprendizagem do sujeito". De acordo com Ferreiro:

[...] a aprendizagem da leitura e da escrita não se dá espontaneamente; ao contrário, exige uma ação deliberada do professor e, portanto, uma qualificação de quem ensina. Exige planejamento e decisões a respeito do tipo, frequência, diversidade, sequência das atividades de aprendizagem. Mas essas decisões são tomadas em função do que se considera como papel do aluno e do professor nesse processo; por exemplo, as experiências que a criança teve ou não em relação à leitura e à escrita. Incluem, também, os critérios que definem o estar alfabetizado no contexto de uma cultura (Ferreiro, 1990, p. 32).

Para Ferreiro e Teberosky (1989), a aquisição da leitura e da escrita depende dos processos de aprendizagem do indivíduo, pois ela ocorre internamente. Ou seja, cada sujeito apresenta esquemas próprios para a aprendizagem em suas particularidades e especificidades e o método que é adequado para um indivíduo, pode não ser tão eficiente para o outro. Segundo as autoras, não há um método determinado para aprendizagem de algumas competências, portanto, deve ser utilizado o método que favoreça e estimule os processos de aprendizagem do sujeito.

Ainda, de acordo com Mendes (2017, p. 9): [...] "nota-se que a aquisição da leitura e da escrita é um processo amplo e complexo por apresentar algumas especificidades em tal processo de aprendizagem e, também, por depender das particularidades de cada sujeito".

Magda Soares (2004) também defende que: 
[...] Não há um método para a aprendizagem inicial da língua escrita, há múltiplos métodos, pois a natureza de cada faceta determina certos procedimentos de ensino, além de as características de cada grupo de crianças, e até de cada criança, exigir formas diferenciadas de ação pedagógica (Soares, 2004, p.15-16).

Para a aquisição da leitura e da escrita, Soares (2004) afirma que um dos elementos fundamentais é a aprendizagem do código da escrita. Nos estudos de Mendes (2017, p. 10), "após a aprendizagem do código, é possível que a criança aprenda a codificar (escrita) e a decodificar (leitura). Entretanto, para que a criança seja capaz de codificar e decodificar é necessário que haja a compreensão acerca das relações grafofônicas".

De acordo com Soares (2004, p. 14), essa compreensão diz respeito às relações entre grafema e fonema, isto é, as "relações entre o sistema fonológico e os sistemas alfabético e ortográfico".

Magda Soares (2004) defende que a consciência fonológica e fonêmica são aspectos fundamentais para o processo de alfabetização. Para a autora, a criança compreende que a forma gráfica (escrita) é uma representação da forma sonora (fala).

Nas análises de Mendes:

Adams, Foorman, Lundberg e Beeler (2006) destacam, ainda, que a consciência fonológica é ampla e, assim, contempla diversos tipos de consciências dos sons do sistema de uma língua como, por exemplo, a consciência fonêmica, a consciência silábica e a consciência intra-silábica. Portanto, tais autores enfatizam que é imprescindível a aprendizagem que os sons das letras são os mesmos sons utilizados para a fala para que, em seguida, ocorra a compreensão do princípio alfabético (Mendes, 2017, p. 11).

Para a pesquisadora Carmen Sá Brito Sigwalt:

[...] o objetivo de desenvolver a consciência fonêmica consiste em preparar o aluno para descobrir o princípio alfabético, ou seja, descobrir que letras representam fonemas. Gradativamente o aluno vai percebendo que quando muda a letra, muda o som e o sentido da palavra (Sigwalt, 2013, p. 74).

Sigwalt (2013) afirma também que o sistema alfabético associa um componente visual fonêmico e um componente visual gráfico, correspondendo ao sistema grafofonêmico. Portanto, para a compreensão do princípio alfabético são necessários três fatores:

1 - A consciência de que é possível segmentar a língua falada em unidades distintas; 2 - A consciência de que essas mesmas unidades se repetem em diferentes palavras faladas; 3 - O conhecimento das regras de correspondência entre grafemas e fonemas (Sigwalt, 2013, p. 74).

Para exemplificar como se realiza esse processo, destacamos no Quadro 1as oito técnicas de ensino utilizadas para o desenvolvimento da consciência fonêmica: 
Quadro 1: As oito técnicas mais usuais para desenvolver consciência fonêmica.

\begin{tabular}{|c|c|c|}
\hline Nome da técnica & Em que consiste & Exemplo \\
\hline Isolar fonemas & Reconhecer sons individuais. & $\begin{array}{l}\text { Professor: Qual é o primeiro som } \\
\text { da palavra moça? Aluno: O } \\
\text { primeiro som da palavra moça é } \\
/ \mathrm{mmmm} / \text {. }\end{array}$ \\
\hline Identificar fonemas & $\begin{array}{l}\text { Reconhecer o mesmo som em } \\
\text { palavras diferentes. }\end{array}$ & $\begin{array}{l}\text { Professor: que som é igual nas } \\
\text { palavras pato, paca, pedra? Aluno: } \\
\text { o primeiro som, /p, é o mesmo. }\end{array}$ \\
\hline Categorizar fonemas & $\begin{array}{l}\text { Reconhecer a palavra que tem som } \\
\text { diferente. }\end{array}$ & $\begin{array}{l}\text { Professor: que palavra tem som } \\
\text { diferente: rato, paca, pedra? } \\
\text { Aluno: } \mathrm{r} / \mathrm{a} / \mathrm{t} / \mathrm{o} / \mathrm{tem} \text { som diferente. }\end{array}$ \\
\hline Sintetizar fonemas & $\begin{array}{l}\text { Combinar fonemas que ouviu para } \\
\text { formar uma palavra. }\end{array}$ & $\begin{array}{l}\text { Professor: } \quad \text { que } \\
\text { /c/h/u/v/a/? } \\
\text { chuva. }\end{array}$ \\
\hline Analisar fonemas & $\begin{array}{l}\text { Separar uma palavra em seus } \\
\text { distintos sons, contando ou batendo } \\
\text { palmas a cada som. }\end{array}$ & $\begin{array}{l}\text { Professor: Quantos sons existem } \\
\text { na palavra gato? Aluno: } / \mathrm{g} / \mathrm{a} / \mathrm{t} / \mathrm{o} / \text {. } \\
\text { Quatro sons. }\end{array}$ \\
\hline Eliminar fonemas & $\begin{array}{l}\text { Reconhecer a palavra que sobra } \\
\text { quando se elimina um fonema. }\end{array}$ & $\begin{array}{l}\text { Professor: Como fica chuva sem } \\
\text { /ch/? Aluno: chuva sem /ch/ fica } \\
\text { uva. }\end{array}$ \\
\hline Acrescentar fonemas & $\begin{array}{l}\text { Criar novas palavras acrescentando } \\
\text { um fonema a uma palavra dada. }\end{array}$ & $\begin{array}{l}\text { Professor: Que palavra eu formo } \\
\text { acrescentando o som } / \mathrm{k} / \text { mais asa? } \\
\text { Aluno: Casa. O som } / \mathrm{k} / \text { mais asa } \\
\text { forma a palavra casa. }\end{array}$ \\
\hline Substituir fonemas & $\begin{array}{l}\text { Substituir um fonema por outro para } \\
\text { formar novas palavras. }\end{array}$ & $\begin{array}{l}\text { Professor: A palavra é mato. } \\
\text { Coloque /p/ no lugar do } / \mathrm{m} / \text {. Qual } \\
\text { a palavra? Aluno: Pato. A palavra } \\
\text { é pato. }\end{array}$ \\
\hline
\end{tabular}

Fonte: Sigwalt (2013, p. 75).

O quadro acima descreve a realização de atividades orais que devem preceder o processo de alfabetização. Nas análises de Mendes (2017, p. 11), [...] “o ensino e a aprendizagem da consciência fonológica e das relações grafofônicas aceleram o processo de aquisição da leitura e da escrita”. Assim, o método de alfabetização por meio da consciência fonológica, torna-se essencial para a aquisição da leitura e da escrita.

Vale ressaltar que os estudos acerca da psicogênese da língua escrita, nas relações entre o pensamento e a linguagem, são baseados nos pressupostos construtivistas do psicólogo Jean Piaget. Para Piaget, "o sujeito cognoscente, em interação com os objetos de conhecimento, os reconstrói, e, no caso da escrita, sua aprendizagem culmina quando a criança chega à noção de que ela representa a fala" (Milmann, 2013, p. 26-27).

As psicolinguistas argentinas Emília Ferreiro e Ana Teberosky (1989), defendem que as crianças passam por diferentes estágios ao longo do desenvolvimento da escrita. As autoras, tomando como referência a teoria do desenvolvimento cognitivo elaborado por Jean Piaget, propuseram uma teoria de apropriação do conhecimento dos níveis de leitura e escrita, conhecida como "Psicogênese da escrita".

Ferreiro e Teberosky (1989), apresentam a escrita em 5 níveis do desenvolvimento. O Quadro 2 apresenta os estágios da escrita segundo as autoras: 
Quadro 2: Estágios de escrita segundo Ferreiro e Teberosky.

1) Nível garatuja: há uma diferenciação entre as duas modalidades de representação gráfica, o desenho e a escrita, através do uso de linhas onduladas e garatujas;

2) Estágio pré-silábico: a criança ainda não compreende o aspecto fonológico da escrita, contudo, já compreende a natureza simbólica da escrita, como o número de linhas, a variedade de letras etc.

3) Estágio silábico: nível fundamental para o desenvolvimento da escrita, pois a criança começa a concentrar a atenção nas diferenças fonológicas entre as palavras, cria-se, portanto, condições para a descoberta do princípio alfabético.

4) Nível silábico-alfabético: ocorre a passagem da hipótese silábica para a alfabética, através da escrita pelas unidades sonoras, os fonemas da sílaba;

5) Fase alfabética: ocorre quando a criança já é capaz de operar unidades maiores do que o grafema fonema, incluindo então, morfemas e sílabas ou parte das sílabas e já ocorre o final do processo de compreensão do sistema de escrita.

Fonte: Oliveira (2018, p. 34).

Para Ferreiro e Teberosky (1989), a passagem por todos os níveis ocorre de um nível para outro e demora em média dois meses e meio em cada estágio. No entanto, segundo Oliveira (2018, p. 34), as autoras defendem também que [...] "os níveis não são fixos e completos, ou seja, algumas crianças podem seguir somente três níveis evolutivos e outras, somente dois níveis, sendo possível existir salto de níveis, como por exemplo pular do nível pré-silábico ao alfabético".

Outro ponto a destacar é que, por mais que entendamos o quanto o método de alfabetizar por meio da consciência fonológica, possa influenciar positivamente no processo de alfabetização. Devemos compreender "que podem surgir dificuldades no processo de aquisição da leitura e da escrita quando a consciência fonológica não for bem desenvolvida nas crianças" (Mendes, 2017, p. 12).

Diante disso, para sanar as dificuldades que surgem no processo de aquisição das competências de leitura e de escrita, é fundamental a participação do psicopedagogo. No sentido de que, a intervenção psicopedagógica, [...] "poderá sanar as dificuldades apresentadas pela criança em relação à leitura e à escrita, visto que tais competências são fundamentais para a continuidade da trajetória escolar da criança e, também, para a prática social de tal sujeito” (Mendes, 2017, p. 12).

\section{A Intervenção Psicopedagógica e a Alfabetização}

A Psicopedagogia é uma ciência que visa compreender como ocorre a aprendizagem humana, oferecendo respaldos teóricos que busquem analisar as dificuldades de aprendizagem. No processo de aquisição da leitura e da escrita, a atuação psicopedagógica, pode intervir sobre os problemas de aprendizagem de modo a contribuir e melhorar a aprendizagem das crianças na alfabetização.

De acordo com Góes e Pires (2015), a intervenção psicopedagógica apresenta um caráter primordial para as crianças que apresentam dificuldades escolares de qualquer natureza. Sendo que, a atuação psicopedagógica, [...] "não está limitada apenas às dificuldades de aprendizagem, pois, o profissional da área trabalha tanto de forma interventiva, quanto preventiva, visando proporcionar e facilitar o processo de aprendizagem" (Góes; Pires, 2015, p. 123). Nesse sentido, o acompanhamento psicopedagógico tem como objetivo o desenvolvimento de competências e habilidades, no intuito de sanar as dificuldades apresentadas pelo aprendiz. 
A professora Eloísa Quadros Fagali (2006) defende que a intervenção psicopedagógica possui um caráter terapêutico, e a ação do psicopedagogo deve ser a de acolher e possibilitar a aprendizagem e o desenvolvimento do indivíduo.

Assim, essa intenção terapêutica consiste em:

1- $\quad$ Acolher o outro, o diferente, o fragmentado e cristalizado, respeitando suas singularidades;

2- $\quad$ Abrir espaço para que o outro possa se revelar criador construtor de si próprio e do seu conhecimento;

3- Manter diálogos entre aqueles envolvidos com a dinâmica relacional, proporcionando diferentes formas de contato com o mundo interno e externo para integrar o "pensar" e o "emocionar" (Fagali, 2006, p. 5).

É possível notar que a intervenção psicopedagógica visa a mudança e a transformação do sujeito, através da sua aprendizagem e de seu desenvolvimento. Dessa forma, Souza (2017, p. 6) afirma que o psicopedagogo, ao ter contato com seu alunado, "deve levar em consideração as realidades externas e internas desse sujeito aprendente, cabe a ele atuar em prol da solução ou da prevenção dos problemas dos processos do ato de aprender desse indivíduo", mediante a utilização de estratégias interventivas eficientes.

Nas análises da pesquisadora Bárbara Rocha de Souza (2017, p. 5):

[...] o trabalho do psicopedagogo na instituição escolar possui duas naturezas: a primeira delas para os alunos que apresentam dificuldades na escola. Sendo assim, o seu trabalho seria reintegrar e readaptar o discente no contexto de sala de aula, respeitando as suas necessidades, desenvolvendo as suas funções cognitivas, levando-o, gradualmente, para a aquisição da aprendizagem formal. O segundo tipo, o assessoramento dos demais sujeitos envolvidos, como pedagogos, orientadores e professores. O objetivo seria trabalhar as questões das relações vinculares professor-aluno e repensar os procedimentos pedagógicos através da integração do afetivo e do cognitivo, por meio das diferentes áreas do conhecimento.

Góes e Pires (2015, p. 123), ressaltam que "uma das dificuldades mais presente no ambiente escolar é o fracasso na leitura e escrita, que é apresentada principalmente no processo de alfabetização". De acordo com as estatísticas do MEC (Ministério da Educação e Cultura), muitas/os alunas/os chegam aos anos finais do ensino fundamental sem adquirir as competências de leitura e escrita definidas no currículo escolar (Mendes, 2017).

Para Sílvia, Gasparian Colello,

Dados do Instituto Nacional de Estatística e Pesquisa em Educação (INEP) indicam que os índices alcançados pela maioria dos alunos de $4^{a}$ série do Ensino Fundamental não ultrapassam os níveis "crítico" e "muito crítico". Isso quer dizer que mesmo para as crianças que têm acesso à escola e que nela permanecem por mais de 3 anos, não há garantia de acesso autônomo às práticas sociais de leitura e escrita (Colello, 2004, p. 07).

As dificuldades encontradas nos alunos durante o período de alfabetização são constantemente relacionadas à leitura e escrita. Essas dificuldades se manifestam de diferentes formas como, a disortografia, disgrafia, trocas ortográficas, podendo ser superadas no decorrer do período de alfabetização, como no caso de trocas fonêmicas simples ou perdurar por toda uma vida, caso não haja atendimento educacional sistematizado que objetive proporcionar a superação desses problemas

Ferreiro e Teberosky (1990) defendem que é por meio do conflito cognitivo que ocorre o progresso no conhecimento e, consequentemente, a reestruturação cognitiva do sujeito. Assim, de acordo com Mendes (2017, p. 13),

O psicopedagogo deve propor atividades que criem conflito cognitivo na criança. Ao promover tais conflitos, ocorre uma nova reestruturação cognitiva no sujeito e, consequentemente, possibilita o desenvolvimento de algumas competências. 
Para a criação de atividades que criem conflito cognitivo na criança, o psicopedagogo deve entender dos métodos para a intervenção psicopedagógica. Góes e Pires (2015, p. 122) afirmam que: [...] "o profissional da área pode se deparar com diversas crianças que apresentam dificuldades de aprendizagem e estas por sua vez, podem ser alfabetizadas por métodos distintos".

Ainda, segundo as autoras:

A compreensão dos métodos de alfabetização também auxilia o psicopedagogo a realizar orientações adequadas aos professores no ambiente escolar, visando à realização de adaptações curriculares para crianças com deficiência, pois estas precisam de intervenções voltadas para atender as suas necessidades, compostas de estratégias específicas que irão facilitar a aprendizagem das mesmas (Góes; Pires, 2015, p. 122).

Dentre os métodos de alfabetização utilizados, podemos encontrar o método fônico, o tradicional, o sócio interacionista e o TEACCH (Treatment and Education of Autistic and Communication Handicapped Children), conforme o Quadro 3 que apresenta os métodos de alfabetização.

Quadro 3: Métodos de Alfabetização.

\begin{tabular}{|c|l|}
\hline Método fônico & $\begin{array}{l}\text { É a metodologia de ensino da leitura mais adotada nos países } \\
\text { desenvolvidos. O método fônico orienta a criança a associar a } \\
\text { parte sonora da escrita (fonema) ao código gráfico (grafema). }\end{array}$ \\
\hline Método tradicional & $\begin{array}{l}\text { O principal objetivo do método tradicional é alfabetizar } \\
\text { enfatizando a associação entre a parte gráfica e a sonoridade } \\
\text { da língua escrita. Esse método considera a aprendizagem } \\
\text { como um treinamento particular baseado na repetição. }\end{array}$ \\
\hline Método sócio interacionista & $\begin{array}{l}\text { O método sócio interacionista surge com ênfase na interação } \\
\text { social, onde o aprendizado é concebido através da interação } \\
\text { do homem com o mundo. A dinâmica da aprendizagem } \\
\text { adotada por este método se dá por meio de interações mútuas, } \\
\text { nas quais alunos e docentes constroem relações afetivas e } \\
\text { sociais, onde a interação e as trocas de conhecimento ocorrem } \\
\text { em um ambiente potencializador de superações. }\end{array}$ \\
\hline Método TEACCH & $\begin{array}{l}\text { É um método de ensino voltado especificamente para atender } \\
\text { pessoas autistas. A metodologia do TEACCH é recheada de } \\
\text { dinamismo e ludicidade, o que o torna bastante atraente e } \\
\text { agradável para criança autista. Através desses aspectos é } \\
\text { possível criar estratégias que possibilite a criança conquistar } \\
\text { várias habilidades, e uma delas é a de interagir de forma } \\
\text { aceitável, desenvolvendo a comunicação para se relacionar } \\
\text { com outras pessoas, despertando assima autonomia. }\end{array}$ \\
\hline
\end{tabular}

Fonte: Góes e Pires (2015, p. 126-129).

Conforme observado nos estudos realizados no presente artigo, o caminho para a intervenção psicopedagógica, que tenha como objetivo a prevenção e superação das dificuldades no processo de alfabetização, é o conhecimento por parte do psicopedagogo para identificar as dificuldades, as limitações e as necessidades dos aprendizes e, programar, de forma efetiva, os melhores caminhos para o desenvolvimento de suas habilidades, como as de leitura e escrita.

Dessa forma, evidencia-se o importante papel do psicopedagogo, como profissional capacitado para atuar de forma preventiva, e propor estratégias de superação das dificuldades ao diagnosticar os possíveis déficits, e ainda, atuar junto aos demais profissionais envolvidos para redefinir as estratégias de ensino, considerando as dificuldades e potencialidades dos seus discentes (Santos, 2017). 


\section{Considerações Finais}

No desenvolvimento desta pesquisa, compreendemos que a prática psicopedagógica é fundamental no processo de ensino e aprendizagem em todos os seus aspectos, pois envolve diferentes recursos pedagógicos, além da atuação de outros profissionais cujo objetivo seja suprir as necessidades dos aprendizes frente as dificuldades no processo de construção da aprendizagem.

Nesse sentido, a intervenção psicopedagógica poderá sanar as dificuldades apresentadas pela criança em relação à leitura e à escrita, visto que tais competências são fundamentais para a continuidade da trajetória escolar da criança e, também, para a prática social de tal sujeito (Mendes, 2017).

No entanto, para a eficiência da intervenção psicopedagógica no processo de ensino-aprendizagem, especificamente na alfabetização, é fundamental que o psicopedagogo entenda as especificidades de cada indivíduo, considerando que a aquisição da aprendizagem está intrínseca ao sujeito, ou seja, ela ocorre internamente.

Assim, cada sujeito apresenta esquemas próprios para a aprendizagem, e não se pode considerar que um único método de alfabetização será eficiente para todos os alunos. Diante dessa necessidade, cabe ao psicopedagogo conhecer métodos, técnicas, instrumentos distintos para o processo de construção do conhecimento. Como também, o profissional deve levar em consideração as realidades externas ao indivíduo, atuando em prol da solução ou prevenção dos problemas de aprendizagem, mediante a utilização de estratégias interventivas eficientes.

Diante disso, esta pesquisa pretendeu delinear os objetivos da atuação psicopedagógica no processo de alfabetização. No entanto, compreendemos que o assunto não se esgotou por completo, mas há ainda muito por se pesquisar, diante da crescente defasagem da aprendizagem principalmente na leitura e na escrita do alunado brasileiro. Assim, este estudo visa despertar o interesse de diferentes pesquisadores, para que novas investigações sejam realizadas no âmbito da atuação do psicopedagogo nas mais diferentes áreas do ensino, tendo como meta identificar as dificuldades de aprendizagem e também apontar caminhos para a superação dos problemas encontrados.

\section{Referências}

Colello, S. M. G. (2004). Alfabetização e letramento: repensando o ensino da língua escrita. Revista Videtur, 27(29), 43-52.

Fagali, E. Q. (2006). Múltiplos sentido do terapêutico: intervenções psicopedagógicas em diferentes contextos e influências das forças culturais. Revista Psicopedagogia, 23(70), 2-14.

Ferreiro, E.; T., Ana (1979). Los sistemas de escritura en el desarrollo del niño. Siglo XXI.

Ferreiro, E.; \& Teberosky, A. (1990). Psicogênese da língua escrita. Artes Médicas, 1990.

Góes, F. K. F. S.; \& Pires, T. S. J. P. (2015. Formação Psicopedagógica: a importância dos métodos de alfabetização. Revista Campo do Saber. 1(2), $120-143$.

Mendes, B. V. (2017). Intervenção Psicopedagógica na aquisição da leitura e escrita: desenvolvimento da consciência fonológica. Trabalho de Conclusão de Curso. 44 f. Universidade de Brasília. Brasília.

Milmann, E. (2013). Poética do letramento: problemas de escrita um enfoque da psicopedagogia na educação inclusiva. Tese (Doutorado). 204 f. Universidade Federal do Rio Grande do Sul. Porto Alegre.

Ministério Da Educação (2021). http://portal.mec.gov.br/.

Moura, D. C. (2001). Por trás das letras: o ensino do sistema de notação alfabética na Educação de Jovens e Adultos. Dissertação (Mestrado em Educação) Centro de Educação, Universidade Federal de Pernambuco, Recife.

Niemann, F. A.; \& Brandoli, F. (2012). Jean Piaget: um aporte teórico para o construtivismo e suas contribuições para o processo de ensino e aprendizagem da Língua Portuguesa e da Matemática. IX ANPED SUL Seminário de Pesquisa em Educação da Região Sul, p. 01-14.

Oliveira, E. S. D. (2018). Avaliação da consciência sintática no âmbito das discussões sobre a predição de aprendizado inicial da leitura e da escrita. Dissertação (Mestrado). 144 f. Universidade Estadual do Sudoeste da Bahia. Vitória da Conquista.

Oliveira, S. A. (2004). O ensino e a avaliação do aprendizado do sistema de escrita alfabética numa escolarização organizada em ciclos. Dissertação (Mestrado em Educação) - Centro de Educação, Universidade Federal de Pernambuco, Recife. 
Research, Society and Development, v. 10, n. 5, e39210515173, 2021

(CC BY 4.0) | ISSN 2525-3409 | DOI: http://dx.doi.org/10.33448/rsd-v10i5.15173

Pereira, A. S. et al. (2018). Metodologia da pesquisa científica. UFSM.

Piaget, J. (1987). O nascimento da inteligência na criança. (4a ed.), Guanabara.

Santos, D. (2017). Contribuições da psicopedagogia clínica na dificuldade de leitura: um relato de caso clínico. Trabalho de Conclusão de Curso. 29 f. Universidade de Brasília. Brasília.

Sigwalt, C. S. B. (2013). Distintas perspectivas de aquisição da língua escrita e a formação do professor que busca alfabetizar-letrando. Tese (Doutorado). 224 f. Universidade Federal do Paraná. Curitiba.

Soares, M. (2004). Letramento e alfabetização: as muitas facetas. UFMG: CEALE, Revista Brasileira de Educação, 2004.

Soares, M. (1998). Concepções de linguagem e o ensino da língua portuguesa. In: Bastos, N. B. (Org.). Língua portuguesa: história, perspectivas, ensino. São Paulo: EDUC.

Souza, B. R. (2017). Alfabetização e letramento: o psicopedagogo como agente do processo de ensino. V CONEDU (Congresso Nacional de Educação). Universidade do Estado do Rio de Janeiro.

Teberosky, A. (1989). Psicopedagogia da Linguagem Escrita. Editora da Unicamp, 1989. 